\title{
Analysis of Lake Taihu Eutrophication Data, 1989-1993*
}

\author{
W. N. Vant ${ }^{1}$, Y. Z. Hua ${ }^{2}$, Y. C. Jiang ${ }^{2}$, \\ G. B. McBride ${ }^{1}$, D. S. Roper ${ }^{1}$ and Q. Wang ${ }^{2}$ \\ ${ }^{\prime}$ National Institute of Water and Atmospheric Research, \\ P.O.Box 1 1-1 15, Hamilton, New Zealand; \\ ${ }^{2}$ Wuxi Environmental Protection Bureau and Wuxi Central Monitoring Station \\ for Lake Taihu, Wuxi, Jiangsu, China
}

\begin{abstract}
The water quality of Lake Taihu has declined markedly in the past two or three decades. We used modern non-parametric statistical methods to analyse the water quality record for 19891993 (samples collected at 2-monthly intervals).Phytoplankton blooms have been a particular problem, as the very high peak chlorophyll a concentrations in the Meiliang (up to $0.4 \mathrm{~g} \cdot \mathrm{m}^{-3}$ ) and the coastal regions (up to $0.5 \mathrm{~g} \cdot \mathrm{m}^{-3}$ ) indicate. However, over a large area of the middle of the lake, peak chlorophyll a concentrations were much lower $\left(0.01-0.03 \mathrm{~g} \cdot \mathrm{m}^{-3}\right)$. In this deeper, turbid part of the lake there may often be insufficient underwater light to support rapid phytoplankton growth; grazing by the abundant benthic bivalves may also be important. Total phosphorus $(P)$ concentrations in the coastal waters increased significantly $(p<5 \%)$. Suspended solids concentrations also increased significantly, and as a result transparency decreased. However, phytoplankton probably usually only account for a small proportion of the suspended material, so the parallel increase in total $P$ and suspended solids may be coincidental. Significant increases in chlorophyll a were not observed, but phytoplankton blooms are often short-lived (e.g. days to weeks), and thus may not always be detected by the 2-monthly sampling.
\end{abstract}

Keywords: eutrophication, phytoplankton, nutrients, Taihu Lake

\section{Introduction}

Lake Taihu $\left(31^{\circ} \mathrm{N}, 120^{\circ} \mathrm{E}\right)$ is the third largest lake in China. It has an area of about $2388 \mathrm{~km}^{2}$, and a relatively-shallow mean depth of $2.1 \mathrm{~m}$ (Kira,1984, Shi \& Liang,1987). It is situated on the densely-populated, fertile plain of the delta of the Yangtze River, about $100 \mathrm{~km}$ inland from Shanghai. The Taihu Basin (36 $355 \mathrm{~km}^{2}$, including the $18500 \mathrm{~km}^{2}$ lake catchment: Kira, 1984, Shi \& Liang, 1987) is one of the most rapidly developing areas of China. It has a population of

\footnotetext{
" Received 1997-02-25; accepted 1998-03-27.
} 
more than 30 million people, with 38 cities (including Shanghai, Wuxi, Suzhou, Changzhou, Jiaxing, Hangzhou and Huzhou).

The climate of the region is subtropical, with warm wet summers, and cold dry winters. Annual average rainfall is $1050-1240 \mathrm{~mm}$, depending on location. In an average water year the inflow to the lake is about $8.7 \times 10^{9} \mathrm{~m}^{3}$ (about $30 \%$ of which results from rain falling directly onto the lake), giving a mean inflow rate of about $275 \mathrm{~m}^{3} \cdot \mathrm{s}^{-1}$ and an average hydraulic residence time of about 7 months (Shi \& Liang,1987). The major inflows rise in the mountainous region to the west and south-west of the lake, while the outflow is predominantly from the east coast. However, a complex network of hydraulically-controlled capals and rivers also connects the lake with the Yangtze River and about 180 small lakes and ponds in the basin; both the direction and velocity of flows in this network are variable (reflecting in part the seasonal variability in water load). Wind-generated currents can also be important in this very large, exposed waterbody. Wind waves up to $1 \mathrm{~m}$ in height have been recorded in the middle of the lake, and a permanent thermocline does not form--although temporary stratification can occur on hot summer days (Shi \& Liang,1987).

Lake Taihu is an important water resource. It provides drinking water and water for industry and agriculture, and is particularly famous for its productive aquaculture and fisheries, which supply $25 \%$ of the nation's total freshwater fish (Yu \& Yang,1996). The area provides some of the best-known water-side scenery in China for domestic and foreign visitors. It is also used for wastewater disposal of treated and untreated effluents and sewage (Shun \& Huang,1993), and supports heavy boat traffic. She (1991, map 17) provided an overview of the water quality of Lake Taihu in 1987, using the Chinese system of water quality classification. Based on information from 22 widely-separated sites, no parts of the lake had "First-class" conditions, much of the lake was "Second-class", but the waters near the western shore (three sites) and of the eastern arm (one site) were "Third-class". In addition, a number of the inflowing waters were contaminated or highly-contaminated ("Fourth-class" or worse).

Specific information on eutrophication in the lake was obtained during 1980 (Shi \& Liang, 1987). The average concentration of dissolved inorganic nitrogen $(\mathrm{N})$ was about $0.9 \mathrm{~g} \cdot \mathrm{m}^{-3}$, most $(88 \%)$ of which was present as nitrate. The average concentration of dissolved phosphorus (P) was $0.03 \mathrm{~g} \cdot \mathrm{m}^{-3}$. In both cases concentrations were higher near the inflows than in the centre of the lake. One hundred and fourteen genera of phytoplankton were observed, with cyanophytes, particularly Microcystis aeruginosa and Anabaena spiroides, being dominant. Annual average "biomass" (presumably phytoplankton dry weight) was about $5 \mathrm{~g} \cdot \mathrm{m}^{-3}$ (range $0.2-50 \mathrm{~g} \cdot \mathrm{m}^{-3}$ ). Phytoplankton biomass was highest in the northern Wulihu embayment $\left(\sim 7 \mathrm{~km}^{2}\right)$, with high levels also occurring in the other coastal regions. The biomass in 1980 was described as being nearly 50 times higher than that present in 1960, with much of the increase being due to the increased abundance of cyanophytes, indicative of marked nutrient enrichment and progressive eutrophication. The water was generally turbid, with an average $S e c c h i$ depth of about $40 \mathrm{~cm}$. 
The Wuxi Environmental Protection Bureau and Wuxi Central Monitoring Station for Lake Taihu has been monitoring the water quality of the lake since 1985. Analysis of the dataset has thus far been limited to the calculation of annual means and standard deviations for certain parameters at certain sites. In late 1996 we undertook a joint analysis of the entire dataset. In this paper we describe the record for the important eutrophication variables during 1989-1993, and use modern non-parametric statistical techniques to identify any trends during this period.

\section{Methods}

Twenty sites, identified as "LS1""LS19" and "LS21" (Fig. 1), were visited at two-monthly intervals during 19891993 (i.e., 30 visits). Measurements were made of Secchi depth $(20 \mathrm{~cm}$ black and white disc) and near-surface water temperature and dissolved oxygen (Yellow Springs Instruments probe and meter). Near-surface water samples were collected, and analysed for suspended solids, total $\mathrm{P}$, total Kjeldahl N, nitrate-N and chlorophyll $a$ using Standard Chinese Methods for Water Quality Analysis. We calculated dissolved oxygen as a percentage of its saturation concentration at the measured water temperature

(Benson \& Krause,1984), and total N as the sum of total Kjeldahl $\mathrm{N}$ and nitrate-N.

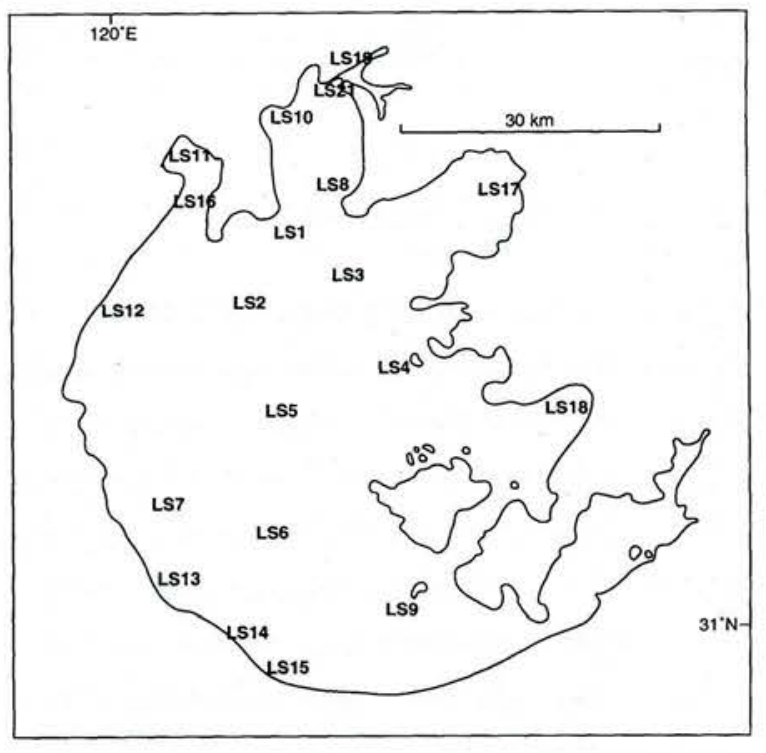

Fig. 1 Lake Taihu, China, showing the location of the 20 monitoring sites.

Tab. 1 Water quality regions of Lake Taihu used in the data analysis (see Fig. 1 for site location).

\begin{tabular}{llr}
\hline Region & Sites & Area $\left(\mathrm{km}^{2}\right.$ \\
\hline Main lake & LS1-7, 9 & 1800 \\
Meiliang & LS8, 10, 19, 21 & 100 \\
Coastal & LS11-18 & 600
\end{tabular}
from that in the other regions. We therefore chose to simplify the analysis by grouping the results according to these regions. For each month the region-average value for a given variable in a particular region was calculated as the arithmetic mean of the values from the individual sites in that region. The monitoring data were analysed statistically to see if trends in deteriorating water quality could be detected. We used the non-parametric trend methods available in the Wqstat II software package (Colorado State University, 1990). These 
methods are more applicable to water quality data than more standard approaches (which assume that the distribution the samples have been drawn from is normally distributed, whereas those for water quality are often distinctly non-normal). The analyses are based on the ranks of the data-the lowest value having the lowest rank, and vice versa--rather than on the actual values of the data. This means that the tests are not strongly influenced by occasional very large or very small values. The analysis is based on the "seasonal Kendall Sen slope estimator and test" (Gilbert 1987, Harcum et al., 1992, Helsel \& Hirsch, 1992), and takes account of the amount of variability that can be attributed to regular seasonal variations.

\section{Results and Discussion}

\subsection{Seasonal variability in water quality}

Water temperature, transparency and plant nutrient concentrations are all key factors controlling phytoplankton growth, while chlorophyll $a$ concentrations are a useful index of phytoplankton biomass. Furthermore, phytoplankton blooms result in increased rates of photosynthesis and respiration, both of which affect dissolved oxygen levels. Seasonal changes in these variables in the three regions are shown in Fig. 2, and Tab. 2 lists the median values.

Water temperature showed a pronounced seasonal pattern (Fig. 2A), with mid-summer values often exceeding $30^{\circ} \mathrm{C}$, and mid-winter values below $5^{\circ} \mathrm{C}$. Seasonality was also evident in suspended solids concentrations, particularly in the main lake and coastal regions, with highest values occurring during winter (Fig. 2B). As a result, transparency was somewhat higher in the summer than winter (Fig. 2C). Values of transparency varied from a low of about $20 \mathrm{~cm}$ in winter to about $70-90 \mathrm{~cm}$ in summer.
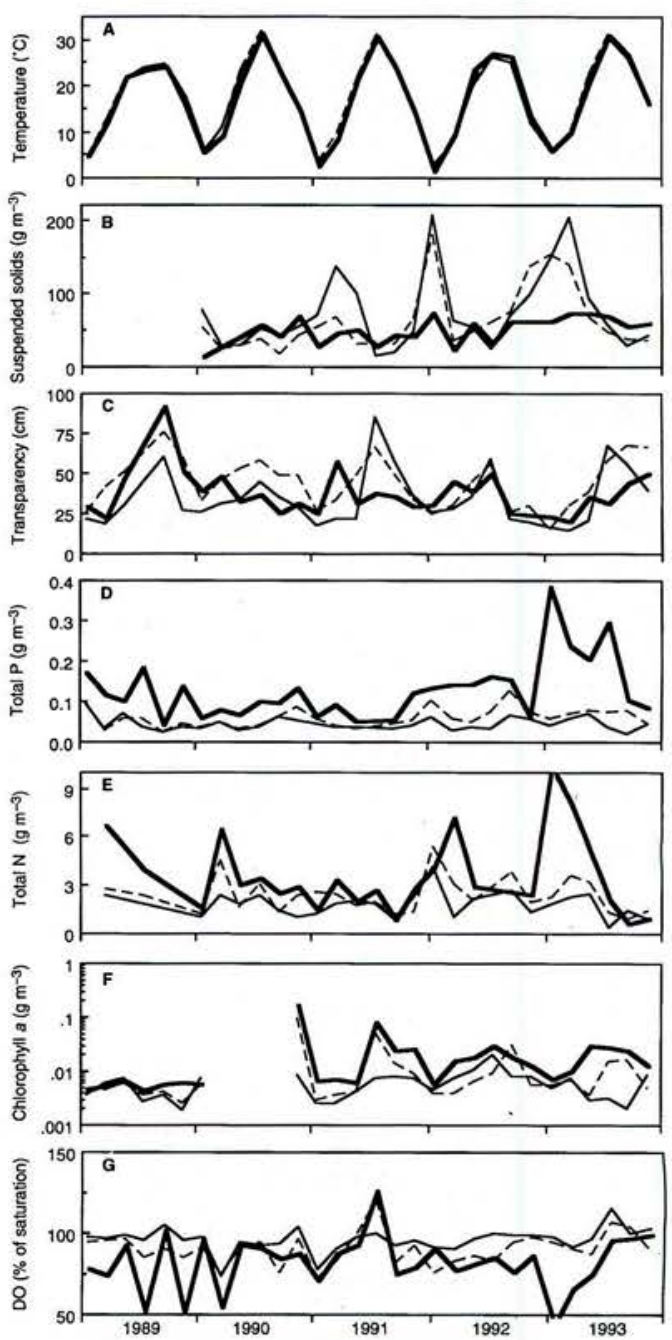

Fig. 2 Water quality in three regions of Lake Taihu, 1989-1993 (solid line: main lake; bold line: Meiliang; dashed line: coastal). A, water temperature; $\mathrm{B}$, suspended solids; $\mathrm{C}$, transparency; D, total phosphorus; $\mathrm{E}$, total nitrogen; F, chlorophyll $a$ (note logarithmic scale); G, dissolved oxygen.

Seasonality was much less apparent in the nutrients total P (Fig. 2D) and total N (Fig. 2E). Total P concentrations were generally higher in Meiliang than in the rest of the lake, and at 0.2 - 
$0.4 \mathrm{~g} \cdot \mathrm{m}^{-3}$, were about twice as high during much of 1993 than previously. Total $\mathrm{N}$ concentrations were also particularly high in this region in early 1993.

Chlorophyll $a$ concentrations generally peaked during summer-autumn (Fig. 2F). Regionalaverage chlorophyll $a$ concentrations were often greater than $0.020 \mathrm{~g} \cdot \mathrm{m}^{-3}$ during summerparticularly in Meiliang and the coastal region, and as low as $0.002 \mathrm{~g} \cdot \mathrm{m}^{-3}$ in winter. At sites in the main lake region, chlorophyll $a$ concentrations were generally low (medians $0.004-0.006 \mathrm{~g} \cdot \mathrm{m}^{-3}$ ), and maximum values during blooms did not exceed $0.030 \mathrm{~g} \cdot \mathrm{m}^{-3}$. In the Meiliang and coastal regions, however, both mean and maximum values were substantially higher (medians 0.005 $0.012 \mathrm{~g} \cdot \mathrm{m}^{-3}$, maxima up to $0.526 \mathrm{~g} \cdot \mathrm{m}^{-3}$ ). In each case the maximum chlorophyll $a$ concentration recorded was observed during summer-autumn (i.e., May-November).

Tab. 2 Median water quality in three regions of Lake Taihu, 1989-1993

\begin{tabular}{lccc}
\hline & Main lake & Meiliang & Coastal \\
\hline Temperature $\left({ }^{\circ} \mathrm{C}\right)$ & 18.4 & 19.5 & 19.0 \\
Suspended solids $\left(\mathrm{g} \cdot \mathrm{m}^{-3}\right)$ & 57 & 55 & 47 \\
Transparency $(\mathrm{cm})$ & 29 & 36 & 46 \\
Total P $\left(\mathrm{g} \cdot \mathrm{m}^{-3}\right)$ & 0.039 & 0.122 & 0.057 \\
Total $\mathrm{N}\left(\mathrm{g} \cdot \mathrm{m}^{-3}\right)$ & 1.86 & 3.00 & 2.31 \\
Chlorophyll $a\left(\mathrm{~g} \cdot \mathrm{m}^{-3}\right)$ & 0.007 & 0.012 & 0.006 \\
Dissolved oxygen $(\%$ saturation) & 97 & 86 & 91 \\
\hline
\end{tabular}

The ratio of the maximum chlorophyll $a$ concentration to the median concentration is an index of the variability in phytoplankton biomass associated with the occurrence of phytoplankton blooms. At sites in the main lake region this ratio was 2.3-7.2, but at sites in the Meiliang and coastal regions the ratio was often greater than 20 (with the largest value--at site LS14--being 105). Phytoplankton blooms in the Meiliang and coastal regions therefore caused chlorophyll $a$ concentrations to be both higher and more variable than those in the main lake.

Dissolved oxygen levels in the near-surface waters varied markedly, with regional means being in the range $40-130 \%$ of saturation concentration (Fig. 2G). Although seasonality was apparent in the record of dissolved oxygen concentrations $\left(\mathrm{g} \cdot \mathrm{m}^{-3}\right.$, data not shown), with highest values occurring during winter, this was largely a function of the seasonality in water temperature (Fig. $2 \mathrm{~A}$ ), and disappeared when the results were adjusted for temperature. Both high and low values of percent of saturation concentration occurred during summer, consistent with its being the season of greatest photosynthetic oxygen production, as well as the time of greatest respiration and decay of the seasonally-increased phytoplankton biomass.

\section{2 Limiting nutrient}

In the absence of other limiting factors, either or both of $\mathrm{N}$ and $\mathrm{P}$ often limit phytoplankton growth in lakes. In analysing lake data it is desirable to be able to identify the limiting nutrient. 
When the ratio of total $\mathrm{N}$ to total $\mathrm{P}$ by weight is in the range 10-17, phytoplankton growth is often found to be balanced with respect to both $\mathrm{N}$ and $\mathrm{P}(\mathrm{OECD}, 1982)$. When the ratio is below these values $\mathrm{N}$ is often limiting, while ratios above these values are often associated with $\mathrm{P}$-limitation.

We calculated the mean value of the ratios of total $\mathrm{N}$ to total $\mathrm{P}$ (both in $\mathrm{g} \cdot \mathrm{m}^{-3}$ ) for each of the three regions of Lake Taihu. The mean value in the Meiliang region was 30 (range 7-78), while it was about 43 in both the main lake (range 11-74) and coastal (range 12-94) regions. These results suggest phytoplankton in Lake Taihu are P-limited.

\section{3 Light-limitation}

As well as nutrients, other factors including insufficient light, rapid flushing and high grazing rates may restrict phytoplankton yields. Some information is available to help assess the likelihood of light-limitation of phytoplankton growth in Lake Taihu. The high suspended solids concentrations (Tab. 2), and the dependence of transparency on these (Fig. 3), mean that suspended particulate material must be responsible for much of the attenuation of underwater light. The suspended particulates include both inorganic silts and phytoplankton biomass. An estimate of the contribution of phytoplankton to the total suspended particulates concentration can be obtained by assuming, conservatively, that chlorophyll $a$ constitutes about $1 \%$ of phytoplankton dry weight (i.e., [phytoplankton dry weight, $\left.\mathrm{g} \cdot \mathrm{m}^{-3}\right]=100 \times\left[\right.$ chlorophyll $\left.a, \mathrm{~g} \cdot \mathrm{m}^{-3}\right]$ ).

We calculated the estimated contribution of phytoplankton biomass to the suspended solids concentrations for the available data from Lake Taihu. On average, phytoplankton biomass comprised about $3 \%$ of the suspended material (maximum $52 \%$, ninety-five percentile $12 \%)$. Biomass was therefore typically only a minor contributor to particulate material in Lake Taihu, but can contribute up to about half the particulate material during a major bloom. The other particulate material was probably mostly inorganic silts, with some organic detritus (including that associated with phytoplankton). This other mate rial--rather than the phyto- plankton biomass--was therefore usually the main cause of light attenuation in Lake Taihu.

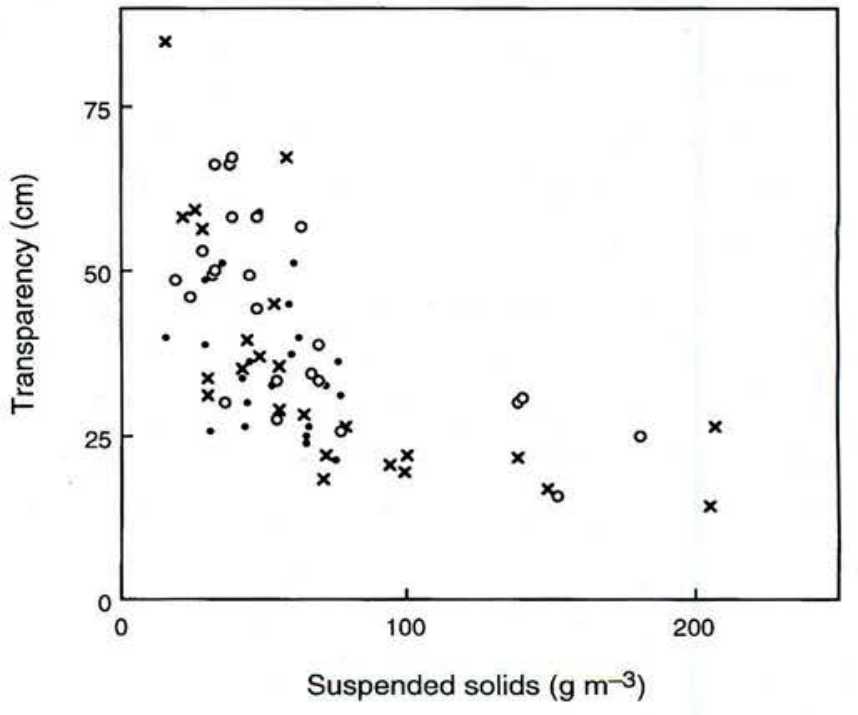

Fig. 3 Suspended solids concentration and transparency in three regions of Lake Taihu, 1989-1993 (crosses: Main Lake; closed circles: Meiliang; open circles: Coastal). 
In many waterbodies the ratio of euphotic depth to water column mixed depth provides a broad index of the amount of underwater light available for phytoplankton growth

(Davies-Colley et al., 1993, p. 114). If the ratio is less than about 0.2 , there is often insufficient light for growth since phytoplankton cells spend much of the time in poorly-lit waters. If the ratio is greater than about 1 there is usually adequate light for growth; at values in the range $0.2-1$ some light-limitation is likely.

In turbid and relatively bright waters like those of Lake Taihu, about $10 \%$ of the incident light is reflected by suspensoids present in the nearsurface waters (Davies-Colley \& Vant, 1988). In such waters the

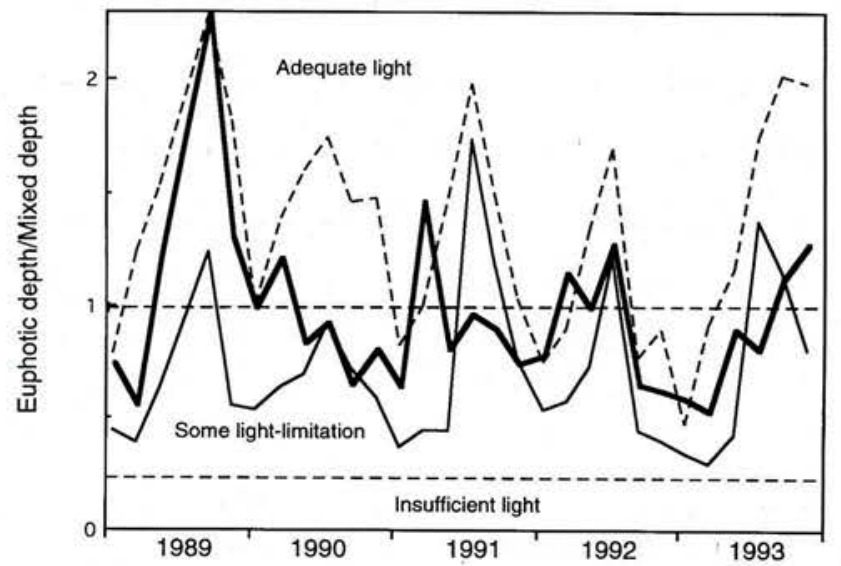

Fig. 4 Ratio of estimated euphotic depth (see text) to mixed depth in three regions of Lake Taihu, 19891993 (solid line: main lake; bold line: Meiliang; dashed line: coastal). Horizontal lines distinguish zones of differing degrees of light-limitation of phytoplankton growth.

euphotic depth- the depth at which photosynthetically available radiation is attenuated to $1 \%$ of its sub-surface value -is generally about 4.5 times greater than the transparency (Davies-Colley \& Vant,1988). We estimated the mean depth of each of the three lake regions as approximately $2.2 \mathrm{~m}, 1.8 \mathrm{~m}$ and $1.5 \mathrm{~m}$ for the main lake, Meiliang, and the coastal region, respectively. In shallow, well-mixed waterbodies like Lake Taihu the average mixed depth is equal to the mean depth. We therefore calculated the ratio of the estimated euphotic depth $(=4.5 \times$ transparency) to the mixed depth for each sampling occasion (Fig. 4).

In each region the ratio of euphotic depth to mixed depth was often greater than 1 (Fig. 4), indicating that light levels were adequate for phytoplankton growth. However, some values of the ratio fell in the range $0.2-1$, namely $55 \%, 43 \%$ and $24 \%$ for the main lake, Meiliang, and coastal regions, respectively. These results indicate that some light-limitation of growth probably occurs for part of the time in the main lake, and to a lesser extent in Meiliang, but that underwater light levels are probably adequate for much of the time in the coastal region. None of the values were less than 0.2 , suggesting that while low light may occasionally restrict phytoplankton growth, it probably does not prevent it altogether.

\section{4 Comparison with eutrophication in lakes elsewhere}

A number of relationships have been reported between phytoplankton biomass (usually measured as chlorophyll $a$ ) and nutrient concentration (usually total P) for lakes in temperate regions (e.g., Dillon \& Rigler,1974, OECD,1982, Pridmore \& McBride,1984, Pridmore,1987). These empirical relationships are obtained by collating information from many different lakes, encom- 
passing a broad range of nutrient enrichment. The relationships are generally determined by linear regression, and indicate how chlorophyll $a$ concentrations depend on nutrient concentrations.

Tab.3 Measured and predicted chlorophyll $a$ concentrations $\left(\mathrm{g} \cdot \mathrm{m}^{-3}\right.$ in three regions of Lake

Taihu, 1989-1993; Growing season defined as the period May-November (from inspection of the temperature and chlorophyll $a$ time series: Fig. 2).

\begin{tabular}{|c|c|c|c|c|}
\hline & & Main lake & Meiliang & Coastal \\
\hline \multirow[t]{2}{*}{ Annual mean chlorophyll $a$} & - measured & 0.006 & 0.024 & 0.013 \\
\hline & - predicted $^{1)}$ & 0.011 & 0.031 & 0.014 \\
\hline \multirow[t]{2}{*}{ Maximum chlorophyll $a$} & - measured & 0.020 & 0.183 & 0.098 \\
\hline & - predicted $^{2)}$ & 0.035 & 0.120 & 0.052 \\
\hline
\end{tabular}

1) annual mean Chl $a=\left(0.28[1000 \times \text { annual mean total } \mathrm{P}]^{0.96}\right) / 1000($ after OECD,1982, p. 54)

2) maximum Chl $a=\left(0.408[1000 \times \text { growing season mean total } \mathrm{P}]^{1.178}\right) / 1000$ (after Pridmore, 1987 ,

Fig. 18.2)

We compared the results for the different regions of Lake Taihu with values predicted from two commonly-used nutrient-biomass relationships (Tab.3). The relationship from OECD $(1982, n=$ 77) was used to predict annual mean chlorophyll $a$ concentrations from annual mean total P concentrations. Reasonably good agreement was obtained between measured and predicted values in the Meiliang and coastal regions, but the measured value for the main lake was about half that predicted.

We also compared the Lake Taihu results with predictions from a relationship between growing season mean total $\mathrm{P}$ concentration and maximum chlorophyll $a$ concentration in 82 diverse lakes (Pridmore \& McBride,1984; Pridmore,1987, Fig. 18.2). Although the measured value in the main lake region was still somewhat lower than predicted (Tab.3), those in the Meiliang and coastal

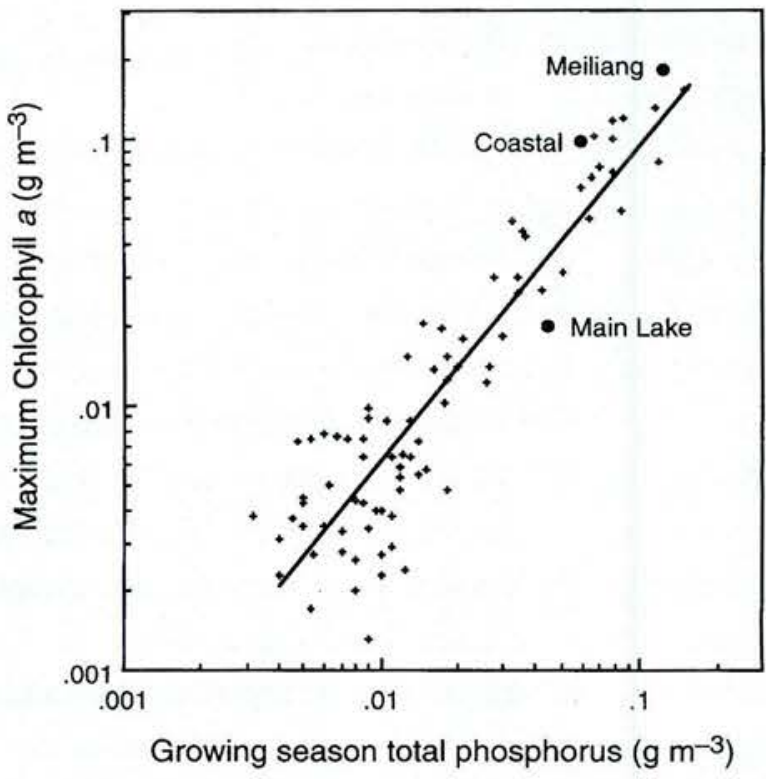

Fig. 5 Relationship between growing season mean total phosphorus concentration and maximum chlorophyll $a$ concentration for 82 temperate zone lakes (redrawn from Pridmore \& McBride,1984, and Pridmore,1987, Fig. 18.2), with results from three regions of Lake Taihu during 1989-1993 superimposed. 
regions were actually higher than predicted (see Fig. 5 also; note that all three Lake Taihu results fell within the $95 \%$ confidence interval for predictions- not shown in the figure). As noted above, the warm water temperatures in Lake Taihu in mid-summer may mean growth there is particularly rapid, resulting in maximum chlorophyll $a$ concentrations which are higher than those in similarly-enriched temperate zone lakes elsewhere. This could account for the higher-thanpredicted values of maximum chlorophyll $a$ in the Meiliang and coastal regions (Fig. 5).

Concentrations of both mean and maximum chlorophyll $a$ in the Meiliang and coastal regions were therefore broadly similar to those observed in similarly nutrient-enriched lakes elsewhere. However, the concentrations of mean and maximum chlorophyll $a$ observed in the main lake were somewhat lower than expected from the total $\mathrm{P}$ concentrations, suggesting other factors may also be controlling phytoplankton growth in this region. As noted above, light-limitation may be more important in the deeper, more turbid waters of the main lake. Furthermore, grazing by suspension-feeding bivalves can limit phytoplankton biomass in lakes (e.g., Madenjian 1995), and such grazers are abundant in Lake Taihu (Shun \& Huang,1993).

Compared with conditions in many other lakes, the maximum chlorophyll $a$ concentrations observed in the Meiliang and coastal regions are very high. Indeed, the maximum concentration in the Meiliang region was higher than that in any of the temperate lakes in the dataset shown in Fig. 5. The general agreement between measured and predicted values of chlorophyll $a$ means total P-chlorophyll $a$ relationships such as those described above can be used to help guide the future management of phytoplankton problems in Lake Taihu. For example, the agreement in Fig. 5 strongly suggests that the maximum chlorophyll $a$ concentrations would be lower if the concentration of growing season total $\mathrm{P}$ were to be lowered. Furthermore, the fact that the exponent in the relationship is close to 1 (Tab.3) suggests the chlorophyll $a$ concentrations would reduce in direct proportion to any reduction in total $\mathrm{P}$ (e.g., a halving in total $\mathrm{P}$ would result in a halving of maximum chlorophyll $a$ ).

\section{5 Trend analysis}

The results of the trend analyses are shown in Tab. 4. Two statistics are given for each region. The first is the estimated slope of the trend-the change per year expressed as a percentage of the overall median value. The second is the attained significance level of the trend test, sometimes called the $p$-value. This is the calculated probability of getting a trend at least as large (positive or negative) as was obtained if in fact there was no trend at all. $p$-values of $<5 \%$ are conventionally regarded as being statistically significant; probabilities of $<10 \%$ and $<20 \%$ are also shown.

The trends in temperature were not significant, and are not considered further. In the main lake region no statistically significant trend was obtained. However, it is notable that the estimated trend slopes are in directions consistent with increasing eutrophication and deteriorating water quality. In the Meiliang region suspended solids showed a statistically significant trend, consistent with the estimated reduction in water clarity. Total P approached a statistically sig- 
nificant upward trend. The strongest evidence of deteriorating water quality and increasing eutrophication was in the coastal region, where statistically significant trends in suspended solids, water clarity and total $\mathrm{P}$ were obtained.

Tab. 4 Trend analyses for three regions of Lake Taihu, 1989-1993; Slopes are given as the change per year, expressed as a percentage of the median value; $p$-values are the significance of the trend (see text) ${ }^{1}$-statistically significant trends shown in bold type. "ns": trend not statistically significant.

\begin{tabular}{lcccccc}
\hline & \multicolumn{2}{c}{ Main lake } & \multicolumn{2}{c}{ Meiliang } & \multicolumn{2}{c}{ Coastal } \\
\cline { 2 - 7 } & Slope & $p$-value & Slope & $p$-value & Slope & $p$-value \\
& & & & & & \\
\hline Temperature & $<1$ & ns & $<1$ & ns & $<1$ & ns \\
Suspended solids & 23 & ns & $\mathbf{1 8}$ & $<\mathbf{5}$ & $\mathbf{2 8}$ & $<\mathbf{5}$ \\
Transparency & -3 & $\mathrm{~ns}$ & -5 & $\mathrm{~ns}$ & $\mathbf{- 8}$ & $<\mathbf{5}$ \\
Total P & 3 & $\mathrm{~ns}$ & 15 & $<20$ & $\mathbf{1 1}$ & $<\mathbf{5}$ \\
Total N & 1 & $\mathrm{~ns}$ & -3 & $<20$ & 3 & $\mathrm{~ns}$ \\
Chlorophyll a & 6 & $\mathrm{~ns}$ & 9 & $<10$ & 7 & $\mathrm{~ns}$ \\
Dissolved oxygen & $<1$ & $\mathrm{~ns}$ & $<1$ & $\mathrm{~ns}$ & 1 & $\mathrm{~ns}$ \\
& & & & & & \\
\hline
\end{tabular}

1) " $<10$ " means $5 \%<p<10 \%$; " $<20$ " means $10 \%<p<20 \%$; "ns" (not significant) signifies that $p>20 \%$

A significant upward trend in total P- as in the coastal region- is the strongest evidence of increasing eutrophication. Increasing suspended solids and decreasing clarity (i.e., transparency) are not necessarily related to eutrophication- especially since the increasing suspended solids is apparently not due to phytoplankton. It could result from increasing catchment loads of silt (i.e., from erosion), or could just be the result of wind re-suspension of bottom sediments by unusual wind events over the latter part of the monitoring period.

It is notable that no significant trends in chlorophyll $a$ were observed. This cannot be taken to mean that eutrophication is not increasing. This is because the onset and decay of phytoplankton blooms can be quite rapid (e.g., within two weeks), and a two-monthly sampling interval may very well miss them altogether. By comparison, total $\mathrm{P}$ concentrations do not fluctuate rapidly, and if they are high one month they are likely to be high the next. In a two-monthly dataset total $\mathrm{P}$ therefore serves as a good measure of eutrophication trends. One other notable feature is that for most variables the trends in each of the three regions were almost all in the same direction. 


\section{Acknowledgments}

Staff of the Wuxi Central Monitoring Station for Lake Taihu undertook the field and laboratory tasks. The involvement of the National Institute of Water and Atmospheric Research in this study was supported by the New Zealand Ministry of Foreign Affairs and Trade (Asia Development Assistance Facility), and facilitated by the Wuxi-Hamilton Sister City relationship.

\section{References}

Benson, B. B., Krause, D. 1984. The concentration and isotopic fractionation of oxygen dissolved in freshwater and seawater in equilibrium with the atmosphere, Limnology and Oceanography, 29: 620-632.

Colorado State University. 1990. Wqstat II. A water quality statistics program, User's manual. Fort Collins, Colorado, USA.. 42 pp.

Davies-Colley, R. J. Vant, W. N. 1988. Estimation of optical properties of water from Secchi disk depths, Water Resources Bulletin. 24: 1329-1335.

Davies-Colley, R. J., Vant, W. N., and Smith, D. G.1993. Colour and clarity of natural waters: science and management of optical water quality, Ellis Horwood, Chichester. $310 \mathrm{pp}$.

Dillon, P. J., and Rigler, F. H. 1974. The phosphorus-chlorophyll a relationship in lakes, Limnology and Oceanography. 19: 767-773.

Gilbert, R. O. 1987. Statistical methods for environmental pollution monitoring, New York, Van Nostrand Reinhold. 320 pp.

Harcum, J. B., Loftis, J. C., and Ward, R. C. 1992. Selecting trend tests for water quality series with serial correlation and missing values, Water Resources Bulletin. 28: 469-478.

Helsel, D. R., and Hirsch, R. M. 1992.Statistical methods in water resources, Amsterdam, Elsevier. 522 pp.

Kira, T.1984. Data book of world lakes, a compilation of physiographic and socio-economic data with emphasis on eutrophication, Shiga Conference'84, Shiga Prefectural Government, Otsu, Japan. 513 pp.

Madenjian, C. P. 1995. Removal of algae by the zebra mussel (Dreissena polymorpha) population in western Lake Erie: a bioenergetics approach, Canadian journal of fisheries and aquatic sciences.52: 381-390.

OECD.1982. Eutrophication of waters: monitoring, assessment and control, Organization for Economic Co-operation and Development, Paris. 154 pp.

Pridmore, R. D. 1987. Phytoplankton response to changed nutrient concentrations. In Vant, W. N. (ed.), Lake managers handbook. Water \& Soil miscellaneous publication 103, National Water and Soil Conservation Authority, Wellington. pp.183-194.

Pridmore, R. D., and McBride, G. B.1984. Prediction of chlorophyll $a$ concentrations in impoundments of short hydraulic retention time, Journal of Environmental Management.19: 343-350. 
She, Z. 1991. Atlas of the natural resources of the Taihu Basin, Compiled by Nanjing Institute of Geography and Limnology. Chinese Academy of Sciences, and Taihu Basin Management Bureau, Ministry of Water Resources, Science Press.

Shi, C., Liang, R.1987. Lake Tai, the limnology of a shallow lake in China, Geojournal.14:319329.

Shun, S. C., and Huang, Y. P. 1993. Taihu Lake, Beijing Oceanic Publishing House, Beijing. 271 pp.

Yu, J., and Yang, J. 1996. National efforts to tackle pollution in Taihu Lake. Newsletter--The International Communication Project. No. 27.

(http://www.comlink.apc.org/fic/newslett/eng/n127/taihu). 